\title{
STUDI EKSPLORASI MANAJEMEN NYERI PADA PASIEN POST OPERASI DENGAN VENTILASI MEKANIK
}

\author{
Rosma Karinna Haq ${ }^{1}$, Suhartini Ismail ${ }^{2}$, Meira Erawati ${ }^{3}$ \\ ${ }^{1}$ Magister Keperawatan, Departemen Ilmu Keperawatan, Fakultas Kedokteran, Universitas Diponegoro, \\ ${ }^{2}$ Divisi Keperawatan Gawat Darurat dan Kritis, Departemen Ilmu Keperawatan, Fakultas Kedokteran, Universitas \\ Diponegoro \\ ${ }^{3}$ Divisi Keperawatan Anak, Departemen Ilmu Keperawatan, Fakultas Kedokteran, Universitas Diponegoro \\ *rosma.karinna@gmail.com
}

\begin{abstract}
Abstrak
Nyeri sebagai salah satu respon yang muncul pada pasien post operasi dapat menimbulkan dampak yang tidak adekuat pada pasien seperti penyembuhan luka yang lama, ketidakpuasan pasien, rawat inap yang lebih lama, dan meningkatnya biaya perawatan. Pasien post operasi dengan indikasi perawatan di ruang ICU seringkali mendapatkan bantuan pernafasan dengan ventilasi mekanik karena masih dalam pengaruh obat anestesi atau terjadi distres pernafasan. Pasien dengan ventilasi mekanik rentan terhadap faktor-faktor yang menimbulkan stres, karena pasien tidak dapat menyesuaikan pernafasan dengan ventilasi mekanik. Kondisi post operasi juga dapat menimbulkan reaksi emosional sehingga menyebabkan perubahan secara fisik dan psikologis, serta mencetuskan ketidaknyamanan pada pasien. Tujuan penelitian ini adalah mengeksplorasi manajemen nyeri pada pasien post operasi dengan ventilasi mekanik di ICU, yang dilakukan pada perawat ICU dengan indepth interview. Tema yang dihasilkan dalam penelitian ini yaitu : (1) Komponen pengkajian nyeri yang adekuat dilakukan perawat pada pasien post operasi dengan ventilasi mekanik, (2) Tindakan yang dilakukan perawat dalam manajemen nyeri pada pasien post operasi dengan ventilasi mekanik, (3) Evaluasi dan re-evaluasi nyeri yang dilakukan perawat pada pasien post operasi dengan ventilasi mekanik. Kesimpulan yang didapatkan dalam penelitian ini adalah manajemen nyeri pada pasien post operasi dengan ventilasi mekanik dilakukan dengan melakukan pengkajian sesuai dengan standar, intervensi manajemen nyeri lebih dominan dilakukan dengan pemberian terapi farmakologi, evaluasi dan re-evaluasi dilakukan setelah pemberian terapi farmakologi dan non farmakologi.
\end{abstract}

Kata kunci: Nyeri; manajemen nyeri; post operasi; ventilasi mekanik, unit perawatan intensif

\begin{abstract}
Explore study pain management in postoperative patients with mechanical ventilation. Pain as one of the responses that appears in postoperative patients can cause inadequate effects on patients such as long wound healing, patient dissatisfaction, longer hospitalizations, and increased maintenance costs. Postoperative patients with indications of treatment in the ICU often get respiratory assistance with mechanical ventilation because they are still under the influence of anesthesia or respiratory distress. Patients with mechanical ventilation are susceptible to stressful factors, because patients cannot adjust breathing with mechanical ventilation. Postoperative conditions can also cause emotional reactions that cause physical and psychological changes, and trigger discomfort in patients. The purpose of this study was to explore pain management in postoperative patients with mechanical ventilation in the ICU, which was performed on ICU nurses by indepth interview. The themes produced in this study are: (1) Adequate pain assessment components are carried out by nurses in postoperative patients with mechanical ventilation, (2) Actions taken by nurses in pain management in postoperative patients with mechanical ventilation, (3) Evaluation and re evaluation of pain performed by nurses in postoperative patients with mechanical ventilation. The conclusion obtained in this study is pain management in postoperative patients with mechanical ventilation is carried out by conducting studies in accordance with the standards, pain management interventions are more predominantly carried out by pharmacological therapy, evaluation and re-evaluation are carried out after administration of pharmacological and non-pharmacological therapies.
\end{abstract}

Keywords: pain; pain management; post operation; mechanical ventilation, intensive care unit 


\section{Pendahuluan}

Nyeri merupakan pengalaman sensorik dan emosional yang tidak menyenangkan yang timbul karena adanya kerusakan atau ancaman kerusakan pada jaringan, baik aktual maupun potensial (Swieboda, 2013). Nyeri sebagai salah satu respon yang muncul pada pasien post operasi dapat menimbulkan stres, sehingga sistem kardiovaskular merespon nyeri dengan mengaktifkan sistem saraf simpatik, sehingga menghasilkan peningkatan detak jantung, tekanan darah, dan kebutuhan oksigen. Nyeri post operasi dapat menimbulkan dampak yang tidak adekuat seperti masalah istirahat dan tidur, penyembuhan luka yang lama, ketidakpuasan pasien, rawat inap yang lebih lama, dan meningkatnya biaya perawatan (Shang \& Gan, 2003).

Ventilasi mekanik merupakan terapi yang biasa diberikan di ICU. Pasien dengan ventilasi mekanik rentan terhadap faktor-faktor yang menimbulkan stres misalnya takut, gelisah, tidak nyaman, cemas, imobilisasi, dispnea, haus, bingung, masalah komunikasi, dan ketidakmampuan relaksasi (Wong et al, 2001). Stres yang dialami pasien dengan ventilasi mekanik salah satunya disebabkan karena pasien tidak dapat menyesuaikan pernafasan dengan ventilasi mekanik dan selama tindakan suction (Mofredj et al, 2016). Ekstubasi yang tidak direncanakan (unplanned extubation) merupakan salah satu kondisi yang paling umum dilakukan pasien dengan ETT (Chacko et al, 2007). Unplanned extubation menyebabkan kesulitan reintubasi, meningkatkan lama hari rawat pasien, dan meningkatkan risiko Hospital Acquired Pneumonia (De Lasence, 2002; Kohne et al, 2018). Pasien yang membutuhkan reintubasi setelah unplanned extubation mempunyai angka mortalitas yang lebih tinggi dibanding pasien yang toleransi terhadap ETT. Penyebab unplanned extubation antara lain pasien gelisah dan tidak mampu mentoleransi pemasangan ETT, serta tidak dapat menyesuaikan pernafasan dengan ventilasi mekanik (Bouza et al, 2007; Krinsley et al, 2005).

Penatalaksanaan nyeri yang adekuat penting dilakukan pada pasien post operasi dan terpasang ventilasi mekanik. Intervensi non farmakologi telah diakui sebagai adjuvan yang penting, sederhana, dan efisien untuk manajemen nyeri. Penggunaan kombinasi metode farmakologi dan non farmakologi menghasilkan kontrol nyeri yang efektif untuk mengurangi nyeri yang dialami pasien (Mofredj, 2016). Perawat dapat memberikan kontribusi yang signifikan untuk melakukan manajemen nyeri pada pasien (Kelly et al, 2010). Tujuan penelitian ini adalah mengeksplorasi manajemen nyeri pada pasien post operasi dengan ventilasi mekanik dengan cara indepth interview pada perawat di ICU.

\section{Metode}

Penelitian ini menggunakan jenis penelitian kualitatif, dengan melakukan studi eksplorasi untuk mendeskripsikan manajemen nyeri pada pasien post operasi dengan ventilasi mekanik di ICU salah satu rumah sakit di Jawa Tengah. Data didapatkan dari hasil indepth interview dengan 5 perawat yang bekerja di ICU. Kriteria inklusi dalam penelitian ini adalah perawat ICU yang bekerja di ICU lebih dari 5 tahun. Kriteria eksklusi dalam penelitian ini adalah perawat yang belum memiliki sertifikat pelatihan nyeri. Hal-hal yang ditanyakan dalam penelitian ini antara lain kompetensi pengkajian nyeri yang dilakukan perawat, intervensi manajemen nyeri, dan evaluasi maupun reevaluasi nyeri. Proses analisa dilakukan dengan cara pengelompokan data hasil wawancara sesuai dengan tema yang muncul.

\section{Hasil}

Hasil indepth interview didapatkan 3 tema, yaitu: (1) komponen pengkajian nyeri yang adekuat dilakukan perawat pada pasien post operasi dengan ventilasi mekanik, (2) tindakan yang dilakukan 
perawat dalam manajemen nyeri pada pasien post operasi dengan ventilasi mekanik, (3) evaluasi dan re-assessment nyeri yang dilakukan perawat pada pasien post operasi dengan ventilasi mekanik.

1. Tema 1 : komponen pengkajian nyeri yang adekuat dilakukan perawat pada pasien post operasi dengan ventilasi mekanik.

Komponen pengkajian nyeri yang dilakukan perawat pada pasien post operasi dengan ventilasi mekanik dilakukan sesuai dengan SPO atau panduan yang berlaku di rumah sakit khususnya ICU. Hal ini didasarkan pada pernyataan partisipan sebagai berikut :

"Pengkajian nyeri pada pasien dengan ventilasi mekanik dilakukan dengan menggunakan CPOT sesuai dengan SPO yang ada."(P2)

"Pasien dengan ventilasi mekanik tidak mampu mengkomunikasikan kebutuhannya, sehingga pengkajian nyeri dilakukan dengan menggunakan CPOT yang terdiri dari beberapa parameter sesuai dengan panduan yang ada."(P4)

"Pengkajian nyeri dilakukan dengan menggunakan CPOT dengan menilai perilaku pasien sesuai dengan indikator penilaian." (P5)

2. Tema 2 : tindakan yang dilakukan perawat dalam manajemen nyeri pada pasien post operasi dengan ventilasi mekanik.

Manajemen nyeri yang dilakukan perawat pada pasien post operasi dengan ventilasi mekanik lebih dominan dilakukan dengan kolaborasi pemberian terapi farmakologi. Hal ini didasarkan pada pernyataan partisipan sebagai berikut :

"Manajemen nyeri pada pasien post operasi dengan ventilasi mekanik sering dilakukan dengan kolaborasi pemberian terapi farmakologi, sedangkan tindakan mandiri perawat dengan terapi non farmakologi belum maksimal dilakukan.”(P1)
"Pasien post operasi seringkali mengalami gelisah karena kondisi penyakitnya atau adanya alat invasif yang terpasang seperti ETT,drain, CVC maupun alat invasif lainnya sehingga pasien cenderung ingin mencabut semua alat invasif tersebut. Oleh karena itu, perawat memberikan restrain secara fisik atau dengan obat sedasi sesuai advis dokter."(P4)

"Manajemen nyeri di ICU lebih dominan dilakukan dengan pemberian obat analgetik atau sedasi sesuai dengan advis dokter. Selama ini, implementasi mandiri yang sudah dilakukan perawat dengan menggunakan teknik relaksasi nafas dalam dan distraksi dengan mendengarkan murottal."(P5)

3 . Tema 3 : evaluasi dan re-assessment nyeri yang dilakukan perawat pada pasien post operasi dengan ventilasi mekanik.

Evaluasi dan re-evaluasi nyeri yang dilakukan oleh perawat hanya dilakukan setelah pemberian terapi farmakologi. Hal ini didasarkan pada pernyataan partisipan, yaitu :

"Perawat melakukan evaluasi nyeri setelah 30 menit setelah pemberian analgetik secara intravena, kemudian perawat melakukan evaluasi kembali skala nyeri dan hemodinamik pasien setiap jam."( $(\mathrm{P} 2)$

"Evaluasi nyeri pada pasien yang diberikan obat analgetik titrasi seperti morphin dilakukan setelah 15 menit sampai dengan satu jam setelah pemberian, kemudian re-evaluasi dilakukan setiap jam."(P4)

"Evaluasi dilakukan segera setelah memberikan terapi relaksasi maupun distraksi pada pasien, namun pemberian terapi non farmakologi tidak secara adekuat menurunkan nyeri pada pasien post operasi dan terpasang ventilasi mekanik."(P5) 


\section{Pembahasan}

1. Tema 1: komponen pengkajian nyeri yang adekuat dilakukan perawat pada pasien post operasi dengan ventilasi mekanik.

Nyeri merupakan manifestasi klinis yang sering terjadi pada pasien dengan ventilasi mekanik dan bersifat individual dengan pengalaman nyeri yang berbedabeda. Nyeri yang terjadi pada pasien dengan ventilasi mekanik disebabkan oleh penyakit patofisiologis, atau dampak dari terapi dan prosedur yang diberikan pada pasien (Cade, 2008). Pengkajian nyeri yang sistematis dan konsisten dibutuhkan pada pasien dengan ventilasi mekanik (Rahu et al, 2010). Sebagian besar pasien yang terpasang ventilasi mekanik tidak dapat mengkomunikasikan rasa nyerinya secara verbal sehingga diperlukan pengkajian nyeri yang terstandar (Coyer et al, 2007).

\section{Critical-Care Pain Observasion}

Tool (CPOT) merupakan instrumen pengkajian nyeri yang terdiri dari 4 item penilaian, dimana setiap item memiliki kategori yang berbeda, yaitu ekspresi wajah, gerakan tubuh, aktivasi alarm ventilasi mekanik, dan ketegangan otot. CPOT dapat digunakan untuk pengkajian nyeri pada pasien bedah dan non bedah yang ditunjukkan dengan nilai interrater reliability yang cukup tinggi (Gelinas et al, 2006). Pengkajian nyeri pada pasien yang tidak mampu melaporkan nyeri secara verbal merupakan kebutuhan utama yang perlu dilakukan secara rutin dan sistematik sebagai bagian dari proses perawatan. Pengkajian tersebut bertujuan untuk menilai nyeri pada pasien yang bersifat individual (Wahyuningsih dkk, 2016).

2. Tema 2: tindakan yang dilakukan perawat dalam manajemen nyeri pada pasien post operasi dengan ventilasi mekanik.

Nyeri akut diidentifikasi sebagai fenomena multidimensi yang terjadi setelah pembedahan atau trauma yang mencakup dimensi sensori dan afektif
(Good, 2009). Manajemen nyeri dilakukan berdasarkan teori keseimbangan antara analgesik dan efek samping yang terdiri dari tiga proporsi yaitu: (1) multimodal intervention , (2) attentive pain management, (3) patient participation. Keseimbangan ini sangat penting karena saat opioid digunakan, risiko atau efek samping seringkali meningkat dan harus dikendalikan. Pengurangan rasa nyeri dan pengontrolan terhadap efek samping pengobatan sangat penting secara etis, kemanusiaan dan alasan ekonomi (Good, 2004).

Multimodal intervention dilakukan dengan manajemen nyeri secara adekuat dengan farmakologi dan non farmakologi, yang berkontribusi dalam pencapaian keseimbangan antara analgesik dan efek samping. Attentive pain management dilakukan dengan pengkajian nyeri yang tepat, identifikasi efek samping, proses intervensi, pengkajian ulang, dan evaluasi. Patient participation dilakukan dengan memberikan edukasi pasien, dimana pasien sangat berkontribusi dalam pencapaian keseimbangan antara analgesik dan efek samping. Konsep teori tersebut digunakan secara langsung pada beberapa nyeri akut setelah prosedur operasi atau trauma pada pasien dewasa. Kolaborasi multidisiplin antara dokter dan perawat dibutuhkan untuk mengatasi nyeri akut pasien, menentukan pengobatan nyeri yang seharusnya diberikan, dan mengatasi efek samping pengobatan yang muncul (Rachmawati, 2008).

3. Tema 3: evaluasi dan re-assessment nyeri yang dilakukan perawat pada pasien post operasi dengan ventilasi mekanik.

Evaluasi dan re-assessment nyeri merupakan bagian dari manajemen nyeri yang dilakukan untuk memfasilitasi penilaian ulang nyeri dan menentukan intervensi lanjutan secara berkala pada pasien. Manajemen nyeri yang berkualitas merupakan proses yang kompleks meliputi skrining, penilaian, dan penilaian ulang 
yang tepat untuk menentukan rencana keperawatan dan tindakan kolaboratif multidisiplin (Herr et al, 2006).

Evaluasi nyeri secara berkala penting dilakukan dengan frekuensi reassessment sesuai dengan kebutuhan pasien. Perawat melakukan evaluasi ulang nyeri dengan interval 8 jam untuk nyeri ringan dan tidak nyeri, 2 jam untuk nyeri sedang, dan setiap jam untuk nyeri berat (Barr et al., 2013).

Manajemen nyeri yang dilakukan dengan tepat dapat meningkatkan kualitas penangana nyeri sehingga dapat menurunkan angka morbiditas dan mortalitas nyeri yang tidak tertangani sehingga dapat menurunkan waktu perawatan pada pasien post operasi (Sadikin, 2015).

\section{Simpulan dan Saran}

Pasien dengan ventilasi mekanik rentan terhadap faktor-faktor yang menimbulkan stres, salah satunya adalah ketidaknyamanan yang disebabkan karena pasien tidak dapat menyesuaikan pernafasan dengan ventilasi mekanik. Kondisi pasca pembedahan merupakan faktor yang dapat menimbulkan ketidaknyamanan karena nyeri akibat trauma jaringan, dimana kondisi tersebut mempengaruhi fungsi fisik, psikis, dan emosional pada individu, dan dapat menyebabkan respon stres.

Manajemen nyeri pada pasien post operasi dengan ventilasi mekanik dipengaruhi oleh beberapa faktor antara lain komponen pengkajian nyeri yang adekuat dilakukan perawat pada pasien post operasi dengan ventilasi mekanik, tindakan yang dilakukan perawat dalam manajemen nyeri pada pasien post operasi dengan ventilasi mekanik, dan evaluasi dan re-assessment nyeri yang dilakukan perawat pada pasien post operasi dengan ventilasi mekanik.

\section{Daftar Pustaka}

Barr, J., Fraser, G.L., Puntillo, K.A., Ely, E.W., Gelinas, C., Dasta, J.F., et al.
(2013). Clinical practice guidelines for the management of pain, agitation, and delirium in adult ICU patients. Crit Care Med, 41, 263306.

Bouza, C., Garcia, E., Diaz, M., et al. (2007). Unplanned extubation in orally intubated medical patients in the intensive care unit: a prospective cohort study. Heart \& Lung J Acute Crit Car, 36(4), 270-6.

Cade, C.H. (2008). Clinical tools for the assessment of pain in sedated critically ill adults. Nurs Critical Care, 13(6):2889.doi:10.1111/j.14785153.2008.00294.x.

Coyer ,F.M., Wheeler, MK., Wetzig, SM., \& Couchman, BA. (2007). Nursing care of the mechanically ventilated patient: What does the evidence say. Part two. Intensive Crit Care Nurs, 23(2):71-80.

Chacko, J., Raju, H., Singh, M., et al. (2007) Critical incidents in a multidisciplinary intensive care unit. Anaesth Intens Care, 35(3), 382-6.

De Lassence, A., Alberti, C., Azoulay, É., et al. (2002). Impact of unplanned extubation and reintubation after weaning on nosocomial pneumonia risk in the intensive care unita prospective multicenter study. $J \mathrm{Am}$ Soc Anesthe, 97(1), 148-56.

Gelinas, C., Fillion, L., Puntillo, K., Viens, C., Fortier M., \& City Q. (2006). Validation of the Critical Care Pain. American Journal of Critical Care, 15(4):18-20.

Good, M. (2009). Pain: a balance between analgesia and side effects. In S. J. Peterson \& T. S. Bredow (Eds.), Middle Range Theories (2nd ed., pp. 
63-81). Philadephia: Lippincott Williams \& Wilkins.

Good, M. (2004). Pain : a balance between analgesia and side effect. Philadelphia: Williams \& Wilkins.

Herr, K., Coyne, P., Key, T., Manworren, R., McCaffery, M., \& Merkel, S. (2006). Pain assessment in the nonverbal patient: Position statement with clinical practice recomendations. Pain Management Nursing, 7, 44-52.

Kelly, D., Jacqueline. (2010). The effect of music on postoperative pain and anxiety. Pain Management Nursing, 11(1), $15-25$. doi:10.1016/j.pmn.2008.12.002.

Kohne, K.M., Hardcastleb, T. (2018). Unplanned extubations in a level one trauma ICU. Southern African Journal of Anaesthesia and Analgesia, 24(4), 103-108. doi.org/10.1080/22201181.2018.148 0192 .

Krinsley, J.S., Barone, J.E. (2005). The drive to survive: unplanned extubation in the ICU. (2005). Chest $J, 128(2), 560-6$.

Mofredj, A., Alaya, S., Tassaioust, K., et al. (2016). Music therapy, a review of the potential therapeutic benefits for the critically ill. Journal of Critical Care, 35, 195-199.

Rachmawati, I.N. (2008). Teori analisis nyeri : keseimbangan antara analgesik dan efek samping. $J$ Keperawatan Indones, 12(2), 129136.

doi:http://dx.doi.org/10.7454/jki.v12i 2.211 .

Rahu, M., \& Grap, M. (2010). Facial expression and pain in the critically ill non-Communicative patient: state of science review. Intensive Critical Care Nursing, 26:343-52.

Sadikin RDH. Asessment nyeri. Bandung: RSUP Dr. Hasan Sadikin; 2015.

Shang, A. B., \& Gan, T. (2003). Optimising postoperative pain management in the ambulatory patient. Drugs, 63,855-867.

Swieboda, P., Filip, R., Prystupa, A., et al. (2013). Assessment of pain: types, mechanism and treatment. Ann Agric Environ Med, 1(1), 2-7. doi:10.1017/CBO9781107415324.0

Wahyuningsih, I.S.., Prasetyo, A., Utami, R.S. (2016). Pengkajian nyeri pada pasien kritis dewasa yang terpasang ventilator. Nurscope Jurnal Keperawatan dan Pemikiran Ilmiah, 2(2), 1-7.

Wong, H.L.C., Lopez, N.V., \& Molassiotis, A. (2001). Effects of music therapy on anxiety in ventilator-dependent patients. Hear Lung J Acute Crit Care, 30(5), 376387. doi:10.1067/mhl.2001.118302. 